COMMENT

DOI: 10.1057/s41599-018-0171-z

\title{
Why we need new architectural and design paradigms to meet the needs of vulnerable people
}

Evangelia Chrysikou ${ }^{1}$

\begin{abstract}
Research on the silver economy shows that products and services, which enhance personal autonomy and social cohesion, are common to successful enterprises that serve the needs of both older adults and their carers. Policymaking focuses on such interventions, mainly from medical-pharmacological and hi-tech perspectives, such as advancements in pharmaceuticals, wearable technologies and e-health applications or robotics. Aspects of the built environment-that is, human-made surroundings-are rarely considered worth exploring. Yet, the fact that we have created buildings, as opposed to many advanced technologies that we are yet to invent, does not necessarily make them fit for purpose for the needs of an ageing population. This is the case in all forms and scales of the built environment, from houses to transportation networks. This article argues that policies and interventions for active and healthy ageing could benefit from a broader integration framework that would allow our built surroundings, of all scales and complexities, to become part of the solution. This could be achieved through new architectural and design paradigms that, contrary to prevailing architectural education and practice, operate in harmony with human perceptions and physiology, especially for vulnerable and older adults. By better understanding the consequences of the built environment on the well-being of the older population and acting on this we could, first, prevent the environment being disabling for vulnerable people and, second, hopefully enable increased autonomy through interventions.
\end{abstract}

\footnotetext{
${ }^{1}$ The Bartlett Real Estate Institute UCL, London, UK. Correspondence and requests for materials should be addressed to E.C. (email: e.chrysikou@ucl.ac.uk)
} 


\section{Background}

ince the 1950s the evolution of medical technologies and low child mortality rates have increased the average lifespan in Europe and the West by about 20 years (United Nations, 2018). This is undoubtedly positive. However, these extra years do not necessarily correspond to years lived in good health. Also, baby-boomers, the largest ever generation, are now entering old age and this phenomenon combined with low fertility rates contributes to the ageing of the population. This creates one of the biggest challenges western societies face: currently about $15 \%$ of the global population is over 60 years of age. In Europe, this figure is $25 \%$ and is expected to rise to $30 \%$ in the next 12 years. In Japan, the over- 60 s already make up $33 \%$ of the population (United Nations, 2015a, 2015b). These numbers threaten the sustainability of healthcare and social services (Mantel, 2001; Hope et al., 2012; Shaw, 2018).

As a result, the need for inclusive and enabling societies and systems becomes apparent. This has created a market for new sectors of the economy to target products and services towards increasing personal autonomy and inclusivity. The focus has been on increasing the integration of medical and technological interventions. However, this article argues that the two alone do not suffice, despite medicine and information technology constituting key areas of infrastructure that contribute to significant advancements to people's health and autonomy. The reason is that they support only part of the infrastructure needed to promote healthy ageing. Although advances in these areas are necessary, the systems fail at the weakest link - the built environment.

The built environment remains our physical context: it is inside the actual physical space where our bodies move and exist. Not all buildings, however, are necessarily fit for purpose, even if they are equipped with universal accessibility devices. For the most vulnerable (this includes people with impairments, frail people, those with multi-morbidities and people with dementia), the physical environment, from private homes to public spaces, might still be disabling. This limits opportunities for meaningful and autonomous lives, contributing to increased loneliness and isolation in old age and can even lead to physical injury and mental illness. Therefore, understanding how our built environment could be designed in harmony with human perception and physiology, especially for vulnerable and older adults, is a link worth exploring.

\section{The architectural status quo in relation to our ageing selves}

Scholars of architecture and architectural theory tend to focus on subjects related to abstract concepts around the process of design, aesthetics and form or the relation of the built environment to socio-cultural phenomena and philosophical streams. Even the criticism of these theories concentrates on these concepts. Meanwhile, user experience in terms of ordinary built environment is rarely the subject of architectural education. Practising architects, especially 'star architects' who have the strongest influence on architectural avant-garde, do not consider the implications of ageing in the design of landmarks, or when they change our cityscapes and transform public and private spaces of high investment, such as airports, regeneration areas, museums, libraries or concert halls. On the contrary, these buildings are commissioned through high-profile international competitions and impressing the judges through photogenic graphics is a stronger priority.

Our houses tend to be less complex in terms of design requirements but are nonetheless significant for our well-being as they are the spaces where we generally spend most of our time. As a type of built environment, they form a significant part of architectural education. Yet, both the architectural theory regarding domestic settings and the building regulations tend to be uninformed by issues related to the interface between human health and interior design. Characteristically, even issues relating to public health, such as indoor air quality and thermal comfort, which can be influenced by architectural materiality and building orientation, are barely considered in planning policies. Yet, because the sustainability of our natural habitat is under threat, scholars of the broader realm of the built environment have established a credible trail of evidence regarding public health aspects and in particular the air-quality and thermal comfort inside buildings. This would involve evidence connecting the increase of air pollutants inside buildings or evidence connecting the exposure to indoor air pollutants and ill health, especially for the most vulnerable groups such as children and older people (Cincinelli and Martellini, 2017). This evidence on the association of public health and quality of the indoor built environment will hopefully influence policy making and improve the quality of lives, especially for the most vulnerable, including people in social housing or care homes.

Yet, our perception of space, the elements in our environment that we find restorative or tiring, helpful or strenuous, the tangible and intangible values of our daily physical realities, change during our lives. This happens together with changes in our bodies. The effect of these changes in perception and physiology on our spatial understanding and interaction should be a major influence for human-centered architecture. However, it would not be an exaggeration to describe this as an undocumented and misunderstood or even ignored stream of architectural research and tutoring. As the theoretical background of the practicing architects has been formed during their time in academia, the practice of architecture could be no exception. In short, due to lack of exposure to the importance of the built environment to human perception and physiology during their education, practicing architects tend not to be aware of the impact of their work on our bodies and minds.

Currently the gap created by inadequate architectural built environments is covered by technology but this is mostly for implementing mechanisms for early intervention in emergencies, such as technologies using sensors, e-health applications and more recently, robots. For example, we can have the means to let somebody know that we fell and hopefully get aid as soon as possible and therefore we could have a better chance of a full recovery. By adding the built environment into the equation we could prevent some of the falls in the first place. This applies to all types of environment from private areas, such as our bedrooms and bathrooms, to public places, and it involves all aspects of the environment, from the building layout to the materials used. Recently a lot has been done to address the quality of our pedestrian paths, especially since Marmot (2015) identified damaged pavements around bus stops as being a major cause of falls among older people. Indeed, in public spaces we see pavements being resurfaced and the addition of benches and seats, making it easier for people to spend time away from their homes. A lack of clean, accessible public toilets also acts as a barrier, restricting potential outdoors activity to an average 30 -min radius around the house (Parent, 2017). These indicate clear links between our physiology, our perception and the built environment.

In what follows I will provide four examples that illustrate this gap between physiology and perception, and the built environment. I will start with examples of intimate and private areas, where we might be on our own; then I will focus on public areas that are vital for some of the most vulnerable, such as healthcare facilities, and finally I will illustrate examples of areas necessary for transport, such as car parks and airports. 

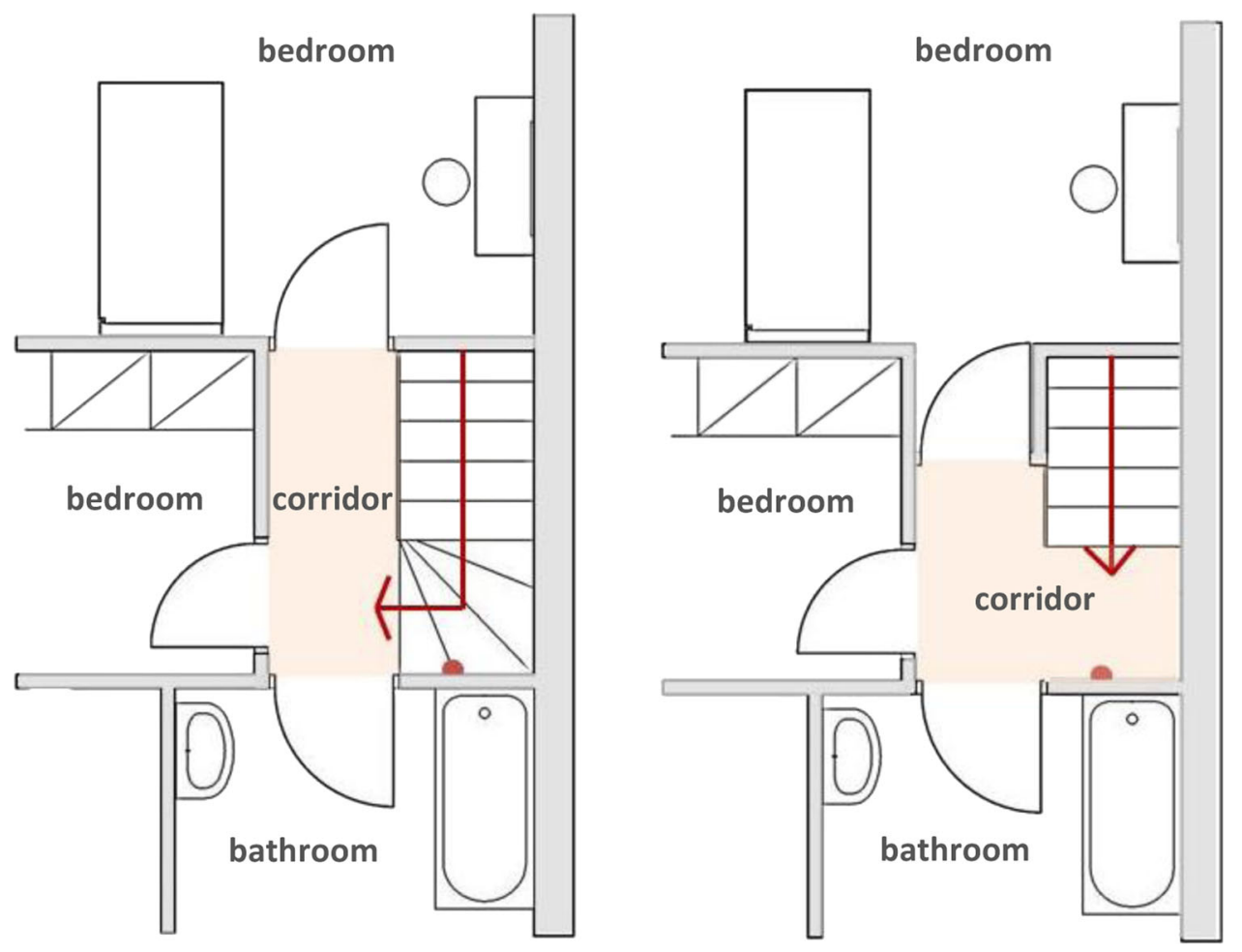

Fig. 1 a, b Current social housing floorplan and hypothetical redesigned floorplan-Part of the upstairs floorplan where a non-frail 79-year-old died following a fall in the night caused by reaching over the staircase for the light switch, showing the position of the light switch, i.e., the red dot on the wall, in relation to the staircase (a) and a reworked plan which could potential reduce the fall risk (b)

\section{Illustrations involving real-life scenarios}

I will use four examples to illustrate the imperative to change the paradigm that our built environment is designed and created without us being asked or directly involved. The first example highlights the complexity of everyday situations and the need for integrated approaches that cut across sectors and disciplines. The second illustrates the reality that our environments tend to be designed and built for people who have good health and cognitive function. Next, even if specialised built environment professionals, such as healthcare architects or medical architecture academics, are aware of the physiological difficulties for specific groups of the population and there are solutions, these solutions might not be common knowledge to the people who design and build our environments, from architects to contractors and builders. Finally, even if these professionals are aware, architectural avant-garde might consider access and neurodiversity as an obstacle to aesthetics and creativity.

The intimate setting. BBC news featured an 87-year-old rescued after being stuck in her bathtub for four days (BBC news, 2016). She 'kept calm' and poured hot water to prevent hypothermia. She was rescued when a waitress noticed that she had broken her habit of visiting a café for three days. The story could raise questions about the direct or indirect implications of the design with regards to social isolation in neighbourhoods, the use of technological devices and preventive environments. First, social isolation and loneliness could be linked to the way that our environments inhibit meaningful social encounters (Griffiths, 2016). Space and its configuration can influence both the frequency and the type of social encounters (Hillier, 1996). This is crucial as the quality and quantity of our social relationships have been linked not only to mental health but also to morbidity and mortality (Holt-Lunstad et al., 2010). Second, in residences, technologies such as cameras or robots that can enter rooms, could keep an eye on us, especially in areas of perceived high risk (Frennert et al., 2012). Finally in this case the design of the bathtub itself could prevent accidents. It could include a nonslippery surface, an ergonomically designed shape for people not to be trapped inside and something to grab and hold that could assist people to get in and out (Granbom et al., 2016; Bernatchez et al., 2017).

The private setting. Building on the previous example, I would like to consider the adequacy of our built environment for the needs of older people. Our building regulations barely mention any measures to mitigate accidents in residential environments. On the contrary, in the area of assisted housing and home environments there is an absence of standards for practice or regulatory structures to inform design professionals, from architects to builders and fitters who perform house renovations on the needs of vulnerable people (Zeeman et al., 2016). As a result, in Western housing stock there are significant problems with environmental barriers for older people, especially for those with functional limitations (Granbom et al., 2016). For instance, there is no mention of anti-slip materials for wet or dry floors, the safety of staircases in relation to their design and to the overall layout or even the strategic placement of light switches. Figure 1 illustrates an example that demonstrates how far standard practice could be from a safe home environment. It shows a social housing floorplan where a non-frail 79-year-old died following a fall during a night visit to the toilet when she was half asleep. Falls are a major concern for older people and the health service. In Europe alone, the cost from falls is 25 billion euros per year, with the built environment being the fourth main reason for these falls occurring and the home being the location $65 \%$ of the time (EuroSafe, 2015). However, the example demonstrates that poor design, in combination with other physical or perception factors -in this case reduced alertness-could add to the risk. Figure 1a 


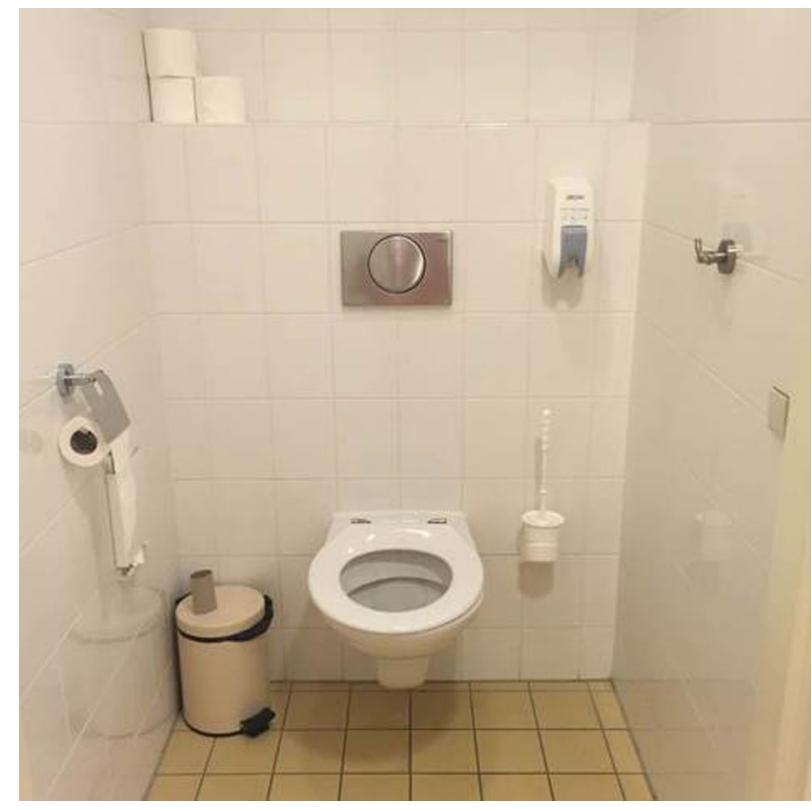

Fig. 2 Restaurant toilet in the dementia village

features the layout and the interior floorplan of a home where a husband and wife lived. The woman got out of bed, walked through the corridor and fell as she tried to reach the bathroom light switch, located by the toilet door over the staircase. Her house was situated inside a larger complex of social housing. Social housing tends to be more regulated than privately-owned residences and subject to public procurement mechanisms. Everything in this house complied with building regulations. Her husband called an ambulance and provided first aid immediately after the fall. In this case sensors and devices that would identify the fall and call for an ambulance would not make any practical difference. However, Fig. 1b illustrates an alternative design where the fall could have been prevented. This solution incorporates a protective man oeuvre zone close to the staircase, separate from the main corridor. The innovation here is that it introduces a safe, no-barrier zone between the bedrooms and the bathroom. The incident was partially the result of design decisions and regulations that were uninformed about the needs of older adults, including perception and mobility challenges.

The healthcare setting. The third example represents a more specialised healthcare architecture. It highlights a key finding from a project investigating the architecture of the first dementia village in the Netherlands (Chrysikou et al., 2016). This is a village-like care home comprising an enclosed network of smaller houses with a protected system of internal roads and several shops and recreation areas. It is a facility for people with dementia to live in and receive care until the end of their lives. The village aims to incorporate in its built environment what was considered state-of-the-art in design for residences for dementia patients. It employs technology, landscaping and a protected environment with positive distraction stimuli, including art used as visual memory aids. Yet, the most private space of the village, the toilet of the common area (Fig. 2), where residents go unescorted, lacks any visual or physical aid for any sort of disability: from partially impaired vision, to mobility, let alone dementia and the multi-morbidities that residents and their visitors might have. Everything follows the same colour scheme, without visual discrimination between vertical and horizontal surfaces or the toilet seat and accessories. Plus, there is a complete absence of any mobility aids for people to support themselves. Literature on dementia might still be limited in relation to the whole spectrum of design decision-making, yet there are publications containing useful design guidelines (Bowes et al., 2016). However, while the British Health Building Notes (Department of Health, 2015), provide the best practice guidance for the design of healthcare facilities, architects do not have to comply. Moreover, the need to implement a detailed guidance on neurodiversity might not reach the briefing process at all.

The public setting. Finally, as a very high profile part of public architecture I will concentrate on the 'extraordinary'. By that I refer to projects created by architects that the architectural establishment considers elite - individuals often known as 'star architects'. These were directly commissioned or are the result of high profile competitions and in these cases the architect involved aims to turn the project into a landmark. These areas could be described as beyond the ordinary, are not modified for people who need care and are for everybody to use. My example here involves a public car park, well known to people interested in architectural avant-garde. A world-leading figure at a stararchitect firm used it as an example of architectural excellence during a presentation to post-graduate architectural students. The famous car park featured floor patterns that could be perceived as changes of level by people with dementia or partial visual impairment and could prove challenging for neurodiversity in general (Department of Health, 2015). Addressing the question about the lack of consideration for neurodiversity, the architect commented that their firm did not design for healthcare but rather buildings such as luxury offices or airports. Yet, literature on tourism suggests that tourism and traveling are beneficial for both healthy ageing and well-being (Morgan et al., 2015) and that airports rely heavily on design means for navigation despite the existence of navigation technologies, especially since older people need architectural information for orientation (Bosch and Gharaveis, 2017). Occasionally, architectural avant-garde has delivered stations and public areas that were deprived not only of assistive devices but even seating. This was to ensure the design would remain unpolluted by such amenities, thus it was protected by contractual agreements (De Morgen, 2011; Mestheneos, 2018; Chrysikou, 2018). At the same time, the silver economy has highlighted the need for medical tourism and tourism for older adults, especially since baby-boomers have both the time and financial means. However, even if that was not the case, we need to design for everybody without demarcation and for the people who design and build our environments to accept that 'everybody', the users of their buildings, are not necessarily as physically or mentally able as them. It is incredibly important that this is taught in architectural schools, where most undergraduates and Masters students are younger than 25 years old and at that age are generally unable to imagine physical or mental decline in older age. We have a responsibility to teach them that 'everybody is not necessarily like me'.

\section{The need for a seamless, integrated environment at the heart of the stakeholder initiatives}

The examples outlined constitute anecdotes regarding the state of the built environment as the global population ages. They represent situations that some older people might face, or even people of all ages at some point in their lives. There are, of course, healthy and fit older people who need supporting too. This has not been ignored. In this case the environment could play a preventive role and strengthen what people already have, for example opportunities for physical exercise, so that they retain their good health, well-being and independence for longer. Initiatives such as the European Innovation Partnership on Active 
and Healthy Ageing (EIP on AHA) aim to do just that (European Commission, 2018a, 2018b). The EIP on AHA is a bottom-up, voluntary initiative of cross-sector stakeholders in collaboration with the European Commission, impacting over two million patients and 30 million citizens by 2015 and covering 1000 regions and 3000 engaged stakeholders (European Commission, 2018a). However, an environment that accommodates for physical and mental impairment can also support everybody else. Those among us who have a more persistent or even temporary vulnerability or impairment might find barriers in the environment that can compromise the quality of their life. The examples mentioned indicate what AGE Platform Europe, a network of non-profit organisations of and for people aged 50+, representing the 190 million citizens aged $50+$ in the European Union, advocates: that universal accessibility aids are not a panacea for the psychosocial integration of older people. It is imperative that both perception and physical needs be addressed especially for people with multi-morbidities who require solutions of increased complexity and variety.

The examples also concern the whole spectrum of the built environment, from private to public and from domestic to institutional. Yet, by failing to acknowledge the perception and physiology changes that occur with age, both our built environments and our building and design professionals are unprepared for the silver autonomy. When we produce facilities where older people move and exist, these need to be seamless: a tapestry of different elements. Gerontologists acknowledge this need to explore ageing in relation to the physical environment and have an established field known as environmental gerontology (Wahl and Oswald, 2010) and have also produced tools to address environmental needs for older people (Iwarsson et al., 2007; Burholt et al., 2016; The Enabler Web Site, 2018; REAT, 2018). However, as of yet these tools have not managed to break the disciplinary silos nor to inform the methods of those who design and construct our neighbourhoods and homes.

\section{A call for paradigm shift}

Currently our built environment is too fragmented and far too partial. It is important to determine who sees it from a nonfragmented perspective and how to bring these people on board: the people who actually experience these spaces daily and encounter the difficulties of old age. We need to involve their advocates and where applicable, the people themselves. We need to include them in the design process as decision makers and we must see our new role as professionals who are asked to do things for them rather than ignore their needs. If we want the built environment not to be our societal weak link, we need to include older and vulnerable adults in the decision-making of our built environment from the very beginning.

Involving end-users is not as difficult as it sounds. In the case of older adults, as a collective force including their advocates and representatives (e.g., AGE Europe and AGE UK) they have all it takes: the energy, the time and the willingness to shape their lives. Involving end-users in their environments from day one is a clear path to success, as my research on environments for acute mentally ill people shows. This is a group that was not considered capable of decision making, silenced and unaccountable (Chrysikou, 2014): even newly built facilities for mental health which received awards for architectural excellence, when end-users were not involved from the onset of the planning stage, performed as badly as asylums in terms of institutional traits displayed in their built environment. The words of John Zeisel on dementia (Zeisel, 2010) demonstrate that even Alzheimer's patients, a group that is often by current specifications and institutions kept inside safe perimeters, with the right multi-disciplinary approach could reclaim their cities. Zeisel's project 'It takes a village' mobilises the entire community and social network in an empowering way of supporting those who suffer from dementia (The I'm Still Here Foundation, 2016).

It also has to be everywhere and in everyplace. We have started seeing stickers of senior-friendly businesses that could provide even small things that can make a huge difference, such as a toilet that you can use even if not a customer. It reminds me of the car sticker 'baby on board'-a brilliant solution without any demarcation. This was a design intervention thought out with care. We need something similar for every design decision, which could impact those who are vulnerable in our societies. For dementiafriendly supermarkets, for instance, staff training is a common measure and is necessary. What was proposed in a design competition for health (Lab4 Living, 2015): an age-friendly till with a non-discriminatory, take-your-time sign over it, a wider space for people to pass next to it and a folded seat for the people still waiting in the queue. The general understanding that ageing is key to inclusion and that it should be taken into account when designing every place of human activity is essential.

For that we need everybody. We must explain to people the benefits of coherent and inclusive societies even if this is through explaining the benefits of the silver economy. Because we need to remember that for the architect to design a 'take-your-time till' we need a supermarket owner to approve it or, even better, request it. The same goes for the car park. It cannot be the fault of the architect if the client who commissioned it was not aware of the importance for all users to safely move within in. There is also the example of airport spaces, where although the technologies might be there in practice, legible buildings are a requirement in the architectural brief. This brings us to the need for informed and inclusive guidelines. Finally, this new paradigm needs to reach the architectural education at the earliest possible stage. The concept of designing whilst considering basic physiological and perception needs as one of the requirements that contributes to successful design should be introduced early on in academic architectural education. These interdisciplinary concepts could then be explored further at postgraduate level in courses relevant to architectural morphology and design and especially those referring to urban planning and complex buildings. Last but not least, these concepts should be provided in courses of continuous education of all professionals working on the planning and the delivery of built environment from planners to builders, especially those involved in retrofits.

Just over two decades ago, when I was an architecture student my professors, in an effort to cultivate our sense of societal responsibility, cited Frank Lloyd Wright's words taken from his own lecture to young architectural students in Chicago, 1931: 'A doctor can bury his mistakes but an architect can only advice his clients to plant vines' (Wright, 1931). They used this particular phrase to emphasise the need for quality aesthetics and to highlight the architect's responsibility for our cityscapes. The example, however, was setting the bar of architectural error on a much less severe, non-life-threatening level than the medical one.

As a teacher I often use the paradigm of the Hippocratic Oath (a phrase that is cited by all physicians), insisting that it should equally apply to architects: 'First do no harm. Then, try to do good'. These two lines, in that order, should support a new paradigm that all architects and professionals of the built environment should be aware of and incorporate in their practice.

Received: 20 November 2017 Accepted: 11 September 2018 Published online: 25 September 2018 


\section{References}

BBC news (2016) Woman stuck in bath for four days 'saved by waitress'. http:// www.bbc.com/news/uk-england-essex-37677809. Accessed 25 Oct 2017

Bernatchez M, Poirier C, Morales E, Maltais M (2017) Rethinking the bathroom for adolescents with cerebral palsy: an exploratory pilot study addressing privacy and independence. J Access Des All 7(2):218-235

Bosch SJ, Gharaveis A (2017) Flying solo: A review of the literature on wayfinding for older adults experiencing visual or cognitive decline. Appl Ergon 58:327-333

Bowes A, Dawson A, Greasley-Adams C, McCabe L (2016) Design of residential environments for people with dementia and sight loss: a structured literature review. Br J Vis Impair 34(3):225-237

Burholt V, Roberts MS, Musselwhite CBA (2016) Older People's External Residential Assessment Tool (OPERAT): a complementary participatory and metric approach to the development of an observational environmental measure. MBC Public Health 16:1022

Chrysikou E (2018) Facilities planning and design for the ageing population. Presentation delivered to eHealth Symposium, Building the European digital health environment-Turning best practice into mainstreamed implementation. Session 2-Housing and Technology in Society, 24 January 2018, London, UK

Chrysikou E, Tziraki C, Buhalis D (2016) Architectural hybrids for living across the lifespan: lessons from dementia. Serv Ind J 38(1-2):4-26. https://doi.org/ $10.1080 / 02642069.2017 .1365138$

Chrysikou E (2014) Architecture for psychiatric environments and therapeutic spaces. IOS Press, Amsterdam

Cincinelli A, Martellini T (2017) Indoor air quality and health. Int J Environ Res Public Health 14(11):1286. https://doi.org/10.3390/ijerph14111286

De Morgan (2011) Senioren eisen zitbanken in station Luik-Guillemins.https:// www.demorgen.be/plus/senioren-eisen-zitbanken-in-station-luik-guilleminsb-1412188587460/. Accessed 18 Feb 2018

Department of Health (2015) Health building note 08-02: dementia-friendly health and social care environments. Crown, UK

European Commission (2018a) European innovation partnership on active and healthy ageing. https://ec.europa.eu/eip/ageing/home_en. Accessed 20 Feb 2018

European Commission (2018b) Research and innovation. https://ec.europa.eu/info/ research-and-innovation_en. Accessed 20 Feb 2018

EuroSafe (2015) Falls among older adults in the EU-28: key facts from the available statistics. EuroSafe, Amsterdam

Frennert S., Östlund B, Eftring H (2012) Would granny let an assistive robot into her home? In: Ge SS, Khatib O, Cabibihan JJ, Simmons R, Williams MA (eds) Social robotics: 4th international conference, Chengdu, China, 29-31 Oct 2012, pp. $128-137$

Granbom M, Iwarsson S, Kylberg M, Pettersson C, Slaug B (2016) A public health perspective to environmental barriers and accessibility problems for senior citizens living in ordinary housing. BMC Public Health 16:772

Griffiths H (2016) Social isolation and loneliness in the UK: with a focus on the use of technology to tackle these conditions. Future Cities Catapult, UK

Hillier B (1996) Space is the machine: a configurational theory of architecture. Press Syndicate of the University of Cambridge, UK

Holt-Lunstad J, Smith TB, Layton JB (2010) Social relationships and mortality risk: a meta-analytic review. PLoS Med 7(7):e1000316

Hope H, Bamford SM, Beales S, Brett K, Kneale D, Macdonnell M, McKeon A (2012) Creating sustainable health and care systems in ageing societies. Report of the Ageing Societies Working Group 2012. The Global Health Policy Summit, UK

Iwarsson S, Wahl HW, Nygren C, Oswald F, Sixsmith A, Sixsmith J, Szeman Z, Tomsone S (2007) Importance of the home environment for healthy aging: conceptual and methodological background of the European ENABLE-AGE Project. Gerontologist 47(1):78-84

Lab4 Living (2015) D4H 24 h design challenge: Team 2-SlowGo. http://research. shu.ac.uk/lab4living/d4h-24h-design-challenge. Accessed 25 Oct 2017

Mantel J (2001) The impact of ageing populations on the economy, a European perspective: from baby boom to baby bust? Geneva Pap Risk Insur Issues Pract 26(4):529-546

Marmot M (2015) The health Gap: the challenge of an unequal world. Bloomsbury Publishing, London
Mestheneos L (2018) Architect Calatrava. Email to E.CHRYSIKOU(e.chrysikou@ucl.ac.uk)

Morgan N, Pritchard A, Sedgley D (2015) Social tourism and well-being in later life. Ann Tour Res 52:1-15

Parent AS (2017) Perspectives from the elderly. Presentation delivered to agefriendly cities conference 2017, 2-4 October, The Hague

REAT (2018) Residential environment assessment tool data site. http://reat.cardiff. ac.uk/. Accessed 15 Feb 2018

Shaw KA (2018) Baby Boomers versus Millennials: rhetorical conflicts and interestconstruction in the new politics of intergenerational fairness. Foundation for European Progressive Studies and Sheffield Political Economy Research Institute, Sheffield

The Enabler Web Site (2018) Providing tools for professional assessments of accessibility problems in the environment. http://www.enabler.nu/. Accessed 15 Feb 2018

The I'm Still Here Foundation (2016) It takes a village. https://www.imstillhere.org/ takes-a-village. Accessed 14 Feb 2018

United Nations (2015a) World population ageing. United Nations, New York, NY United Nations (2015b) World population ageing 1950-2050. United Nations, New York, NY

United Nations (2018) World population prospects 2017. Accessed 20 Aug 2018

Wahl HW, Oswald F (2010) Chapter 8: environmental perspectives on ageing. In Dannefer D, Phillipson C (eds) The SAGE handbook of social gerontology. SAGE Publications, London, p 111-124

Wright LF (1931) Two lectures on architecture, to the young man in architecture. start lecture page 33. The Art institute of Chicago. The Lakeside Press, Chicago

Zeeman H, Courtney J, Hellyer WT (2016) Developing design guidelines for inclusive housing: a multi-stakeholder approach using a Delphi method. J Hous Built Environ 31(4):761-772

Zeisel J (2010) I'm still here-a breakthrough approach to understanding someone living with Alzheimer's. Piatkus, UK

\section{Acknowledgements}

The author greatly appreciates the time and efforts of Keren Fallwell and Peter Humphries for their invaluable contribution to editing and proofreading the paper, as well as the contribution of Eleftheria Savvopoulou to the study. The author also thanks Andrew Edkins for guidance throughout the process.

\section{Additional information}

Competing interests: The author declares no competing interests.

Reprints and permission information is available online at http://www.nature.com/ reprints

Publisher's note: Springer Nature remains neutral with regard to jurisdictional claims in published maps and institutional affiliations.

Open Access This article is licensed under a Creative Commons Attribution 4.0 International License, which permits use, sharing, adaptation, distribution and reproduction in any medium or format, as long as you give appropriate credit to the original author(s) and the source, provide a link to the Creative Commons license, and indicate if changes were made. The images or other third party material in this article are included in the article's Creative Commons license, unless indicated otherwise in a credit line to the material. If material is not included in the article's Creative Commons license and your intended use is not permitted by statutory regulation or exceeds the permitted use, you will need to obtain permission directly from the copyright holder. To view a copy of this license, visit http://creativecommons.org/ licenses/by/4.0/.

(C) The Author(s) 2018 